\title{
'Haemophilus gallinarum' - a Re-examination
}

\author{
By P. J. BLACKALL ${ }^{1 *}$ AND R. YAMAMOTO ${ }^{2}$ \\ ${ }^{1}$ Department of Primary Industries, Animal Research Institute, Yeerongpilly 4105, Australia \\ ${ }^{2}$ Department of Epidemiology and Preventive Medicine, University of California, Davis 95616 , \\ California, USA
}

(Received 12 July 1988; revised 19 October 1988; accepted 25 October 1988)

\begin{abstract}
The growth factor requirements and other properties of two strains of avian haemophili, labelled as 'Haemophilus gallinarum' (an X- and V-factor-dependent organism) and stored since the 1940s and 1950s, were examined. Both strains were X-factor independent and V-factor dependent and possessed the typical biochemical, serological and pathological properties of $H$. paragallinarum. In experiments repeating the tests used in the 1930 s that reported the existence of X-and V-factor-dependent avian haemophili, we found that the methodology used resulted in reference strains of $H$. paragallinarum (X-factor independent and $\mathrm{V}$-factor dependent) appearing to be $\mathrm{X}$ - and $\mathrm{V}$-factor dependent. It is likely that the early descriptions of the aetiological agent of infectious coryza as an X-and V-factor-dependent organism were incorrect.
\end{abstract}

\section{INTRODUCTION}

Haemophilic organisms were first isolated from birds in the 1930s when De Blieck (1932) isolated an organism he termed 'Bacillus haemoglobinophilus coryzae gallinarum' from chickens suffering an upper respiratory tract disease now known as infectious coryza (Yamamoto, 1984). The causative agent was later renamed 'Haemophilus gallinarum' (Elliot \& Lewis, 1934; Delaplane et al., 1934). The earliest characterization study of this disease agent was the work of McGaughey (1932), who reported that his isolates required V-factor but not X-factor for growth in vitro. In contrast, Schalm \& Beach (1936) and Delaplane et al. (1938) reported that their isolates required both $\mathrm{X}$ - and $\mathrm{V}$-factors.

The work of McGaughey (1932) was largely overlooked, and ' $H$. gallinarum' was accepted as the causative agent of infectious coryza and was regarded as requiring both X-and V-factors. However, in the 1960s several studies reported that isolates of the causative agent of infectious coryza required only V-factor and not X-factor for growth in vitro (Page, 1962; Roberts et al., 1964). This resulted in the recognition of a new species, $H$. paragallinarum, for those $X$-factorindependent, $\mathrm{V}$-factor-dependent haemophili that cause infectious coryza (Biberstein \& White, 1969). While case reports, containing few details of the bacteriological methods used, describing the isolation of ' $H$. gallinarum' continue to appear in the literature, for example Malkinson et al. (1987), all detailed bacteriological studies performed around the world have found only $H$. paragallinarum associated with cases of infectious coryza (Hinz, 1973; Narita et al., 1978; Kume et al., 1978; Rimler, 1979; Blackall \& Reid, 1982).

Until the present study, the oldest surviving strains of the causative agent of infectious coryza have dated from the work of Page (1962). Hence, it has not been possible to confirm whether the isolates of the disease agent studied in the 1930s to 1950 s were truly dependent upon both $\mathrm{X}$ - and V-factors. We have recently obtained two strains of avian haemophili, both labelled as ' $H$. gallinarum, isolated during the 1940s and 1950s. In this paper we describe the growth factor requirements, as well as other properties, of these strains. Additionally, we report on a reexamination of the evidence presented in the 1930s for the existence of avian haemophili that require both $\mathrm{X}$ - and $\mathrm{V}$-factors for growth in vitro. 


\section{METHODS}

Organisms. The two ' $H$. gallinarum' strains examined in this study were supplied by Dr M. S. Hofstad. Strain $668 / 398665$ was originally obtained from Dr W. J. Mathey (University of California, Davis) in 1954. The other strain, $737 / 84163$, was originally isolated before 1944 , although precise information is no longer available. Both strains, referred to as the Hofstad strains, were isolated from chickens suffering from infectious coryza. The reference strains of $H$. paragallinarum (0083, 0222, Modesto and IPDH 2403) were obtained from the collection held at the University of California (Davis) except for strain IPDH 2403, which was obtained from Dr K.-H. Hinz (Klinik für Geflügel, Hannover, Federal Republic of Germany). The type strain of Pasteurella avium (ATCC 29546) was obtained from the American Type Culture Collection (Rockville, Maryland) and the type strain of Pasteurella volantium (HIM 745-7; NCTC 3438) was obtained from Dr R. Mutters (Institut für Medizinische Mikrobiologie, Marburg, Federal Republic of Germany). Both these strains were formerly regarded as Haemophilus avium and are harmless commensals of chickens (Mutters et al., 1985).

Media. Test medium agar (Rimler, 1979) supplemented with $1 \%(\mathrm{v} / \mathrm{v})$ heat-inactivated chicken serum and $0.0025 \%(w / v)$ NADH was prepared as described previously (Reid \& Blackall, 1987). This medium is referred to as TM/SN. Other media are described in the following sections. All incubation was performed in an atmosphere of approximately $5 \% \mathrm{CO}_{2}$ at $37^{\circ} \mathrm{C}$, unless otherwise indicated.

Growth factor requirements. The porphyrin test (Biberstein et al., 1963) was performed, using commercially available discs (Remel), to determine any requirement for X-factor. The requirement for $\mathrm{V}$-factor was tested by a supplementation technique (Blackall \& Reid, 1982) using a basal medium, termed TM, which consisted of TM/SN without chicken serum or NADH. The strains were tested for their ability to grow on TM, TM with NADH added (termed TM/N) and TM/SN.

Schalm \& Beach (1936) growth factor tests. (a) Media and growth factors. The basal media were brain heart infusion (BHI) agar and broth (Difco). The sources of X-and V-factors were as described by Schalm \& Beach (1936). Boiled blood agar, regarded as containing X- and V-factor, and autoclaved blood agar, regarded as containing X-factor only, were prepared as described by Schalm \& Beach (1936). For tests in liquid media the sources of X- and V-factor were (Schalm \& Beach, 1936): autoclaved blood extract (X-factor), serum from defibrinated horse blood (X-and V-factors), fresh horse serum (V-factor) and washed horse red blood cells (X-and $\mathrm{V}$-factors). All media were adjusted to $\mathrm{pH} 7 \cdot 5$.

(b) Tests in liquid media. These tests were performed as described by Schalm \& Beach (1936). Briefly, 24-h-old cultures grown on boiled blood agar were lightly suspended in sterile saline and one loopful of the suspension was used to inoculate the six tubes described in Table 2 . After $48 \mathrm{~h}$ incubation at $37^{\circ} \mathrm{C}$ in air, each broth was plated onto boiled blood agar which was incubated for $48 \mathrm{~h}$ and the degree of growth recorded (from 0 , no growth, to $3+$, heavy growth). An additional experiment was performed in which a more complex basal broth, CBB, was used in place of the BHI broth. CBB was prepared as for the complete liquid growth medium known as TMB (Reid \& Blackall, 1987), except that neither NADH nor chicken serum was added.

(c) Tests on solid media. These tests were performed as described by Schalm \& Beach (1936) Briefly, 24-h-old cultures grown on boiled blood agar were lightly inoculated onto the media shown in Table 2 . On one autoclaved blood agar plate, as well as the BHI agar plate, a colony of Serratia marcescens was spotted. Growth on the plates was recorded after incubation as either profuse $(2+)$, satellitic to $S$. marcescens $(1+)$ or absent $(0)$.

Characterization tests. Tests for Gram's reaction, catalase and the ability to grow in air were performed as described previously (Blackall \& Reid, 1982). The ability of the isolates to produce acid from the following carbohydrates was determined using a replica-plating technique (Blackall, 1983): L-arabinose, D-galactose, Dglucose, D-lactose, maltose, D-mannitol, D-sorbitol, D-sucrose, D-trehalose and D-xylose. The Hofstad strains were serotyped using the methods and antisera described by Thornton \& Blackall (1984). The pathogenicity of the Hofstad strains was examined by inoculating each strain into four susceptible chickens as described by Blackall \& Reid (1982) except that both the observation of clinical signs and the necropsy were performed after $2 \mathrm{~d}$.

\section{RESULTS}

\section{Characterization}

All the strains were Gram-negative rods that required only V-factor for growth in vitro by the supplementation test. The $\mathrm{X}$-factor independence of the strains was confirmed by their ability to produce porphyrin from $\delta$-amino-laevulinic acid. The remaining properties of the strains are shown in Table 1. Strain 668/398665 was agglutinin serovar C, while strain $737 / 84163$ could not be serotyped. On the basis of these results, both Hofstad strains were identified as $H$. paragallinarum. Both Hofstad strains produced the typical clinical signs of infectious coryza (swollen sinuses and nasal discharge) and both were recovered from the inoculated chickens. 
Table 1. Differentiating characteristics of the avian haemophili examined in this study

The strains used were: H. paragallinarum - 0083, 0222, Modesto and IPDH 2403; Hofstad - 737/84163 and 668/398665; $P$. avium - ATCC 29546; $P$. volantium - HIM 754-7. All strains were Gram-negative rods that required V-factor but not X-factor for growth. All strains produced acid from glucose and failed to produce acid from arabinose and lactose.
Test
H. paragallinarum
(4)
Hofstad strains
(2)
P. avium
(1)
P. volantium

Catalase
Growth in
$10 \% \mathrm{CO}_{2}$
Air
Acid from
Galactose
Maltose
Mannitol
Sorbitol
Sucrose
Trehalose
Xylose

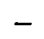

$+$

+
-
-
+
+
+
$\mathrm{v}$
-
-

v, Variable reaction: all strains positive except 0222.
(1) (1)

$+\quad+$

$\begin{array}{ll}+ & + \\ + & +\end{array}$

$\begin{array}{ll}+ & + \\ - & + \\ - & + \\ + & + \\ + & +\end{array}$

Table 2. Results of growth factor tests using the techniques of Schalm \& Beach (1936)

The strains used were: $H$. paragallinarum - 0083, Modesto and IPDH 2403; P. avium - ATCC 29546.

Growth is recorded from 0 , no growth, to $3+$, heavy growth.

\section{Medium}

BHI broth

BHI broth + autoclaved

blood extract (X-factor)

BHI broth + serum from clotted

blood ( $V$-factor)

BHI broth + washed red

blood cells (X-and V-factors)

BHI broth + serum from

defibrinated blood (X- and

V-factors)

BHI broth + autoclaved

blood extract and serum from

clotted blood (X- and V-factors)

Boiled blood agar

(X- and V-factors)

Autoclaved blood agar +

$S$. marcescens colony (X- and

V-factors)

Autoclaved blood agar

(X-factor)

Plain agar $+S$. marcescens colony

(V-factor)

\section{H. paragallinarum}

(3)

0

0

0

$1+$

$3+$

$2+$

$3+$

$1+$

0

0
P. avium

(1)

0

0

$1+$

$1+$

$3+$

$2+$

$3+$

$1+$

o

$1+$
Schalm \& Beach

(1936)*

0

0

0

$1+$

$3+$

$3+$

$3+$

$1+$

0

0

* Results of 'H. gallinarum' as reported by Schalm \& Beach (1936)

\section{Growth factor testing}

As noted above, the supplementation technique and the porphyrin test established that all the strains examined in this study required V-factor, but not X-factor, for growth in vitro. The growth factor tests of Schalm \& Beach (1936) were used to determine the growth factor requirements of $H$. paragallinarum strains 0083, Modesto and IPDH 2403 and $P$. avium ATCC 29546 (Table 2). $H$. paragallinarum strains 0083, Modesto and IPDH 2403 gave the same pattern of results as was recorded in the study of Schalm \& Beach (1936) for their ' $H$. gallinarum' strains. 
Table 3. Results of growth factor tests performed in fluid media using a modification of the techniques of Schalm \& Beach (1936)

Growth is recorded from 0 , no growth, to $3+$, heavy growth.

Medium
Complex basal broth (CBB)
CBB + autoclaved blood extract
(X-factor)
CBB + serum from clotted blood
(V-factor)
CBB + washed red blood cells
(X- and V-factors)
CBB + serum from defibrinated blood
(X- and V-factors)
CBB + autoclaved blood extract and
serum from clotted blood
(X- and V-factors)

Medium

Complex basal broth (CBB)

$\mathrm{CBB}+$ autoclaved blood extract

CBB + serum from clotted blood

(V-factor)

(X- and V-factors)

CBB + serum from defibrinated blood

CBB + autoclaved blood extract and

(X- and V-factors)

$\begin{array}{ccc}\overbrace{0083} \text { M. paragallinarum: } & \text { IPDH 2403 } \\ 0 & \text { Modesto } & 0 \\ 0 & 0 & 0 \\ 1+ & 0 & 1+ \\ 2+ & 1+ & 2+ \\ 1+ & 2+ & 3+ \\ 3+ & 2+ & 2+\end{array}$

The results of the growth factor tests in which the more complete basal broth, CBB, was used in place of BHI broth are shown in Table 3.

\section{DISCUSSION}

The strains of avian haemophili examined in this study, including those isolated before 1960 , were shown to be X-factor independent and V-factor dependent. Indeed, the stored cultures, which appear to be the oldest known strains of avian haemophili, possessed the typical phenotypic characteristics of $H$. paragallinarum, despite being labelled as ' $H$. gallinarum'. These stored strains were originally isolated during the period when the aetiological agent of infectious coryza was widely regarded as being both $\mathrm{X}$ - and $\mathrm{V}$-factor dependent. The fact that these strains were misidentified raised the possibility that other reports of $\mathrm{X}$ - and V-factor-dependent organisms as the cause of infectious coryza were also incorrect.

This possibility led us to re-evaluate the evidence for the existence of 'H. gallinarum'. According to Rimler (1979), there appear to be only two reports in which experimental evidence for the X-and V-factor dependency of the aetiological agent of infectious coryza are presented Schalm \& Beach (1936) and Delaplane et al. (1938). Biberstein \& White (1969) have stated that 'the need for X-factor was convincingly demonstrated' by Schalm \& Beach (1936). Biberstein \& White (1969) noted that 'in the crucial experiment the strains [of Schalm \& Beach (1936)] grew satisfactorily in broth containing 10 per cent fresh horse serum and 10 per cent autoclaved horse blood extract, but not in broth lacking either or both these ingredients'. However, using known $H$. paragallinarum strains, our replication of the experiments of Schalm \& Beach (1936) resulted in the same results as those early workers - an apparent dependence upon both X-and V-factors, an incorrect result. In contrast, when we used the techniques of Schalm \& Beach (1936) with a $P$. avium strain we obtained the expected result, a requirement for $\mathrm{V}$-factor but not $\mathrm{X}$-factor. This occurred both in the 'crucial experiment' referred to by Biberstein \& White (1969) and in the growth factor tests on solid media.

We believe that our study has confirmed that the results obtained by Schalm \& Beach (1936) are reproducible but that the interpretation may have been incorrect. The V-factor-containing media used by Schalm \& Beach (1936) support the growth of $P$. avium but not that of $H$. paragallinarum, despite both organisms requiring V-factor only. Hence, it is entirely possible that the strains examined by Schalm \& Beach (1936) were, in fact, typical $H$. paragallinarum strains. The more stringent growth requirements of $H$. paragallinarum compared to those of $P$. avium appear to be the reason for the failure of the V-factor-containing media of Schalm \& 
Beach (1936) to support the growth of $H$. paragallinarum. This is supported by our finding that the use of a more complete basal medium allows the test methodology of Schalm \& Beach (1936) to predict correctly the growth factor requirements of $H$. paragallinarum strains (Table 3 ).

There is now a large body of evidence that the aetiological agent of infectious coryza has always been $H$. paragallinarum, a V-factor-dependent organism. The few published descriptions of ' $H$. gallinarum' mention properties such as bile solubility (Nelson, 1933), growth under either increased carbon dioxide (Schalm \& Beach, 1936) or moisture (Delaplane et al., 1938) and the ability to reduce nitrate to nitrite (Elliot \& Lewis, 1934) - all of which are compatible with $H$. paragallinarum (Rimler, 1979). Our study has demonstrated that the conclusions of Schalm \& Beach (1936), previously regarded as the most authoritative evidence for the existence of 'H. gallinarum' (Biberstein \& White, 1969), may have been incorrect. As the strains used by Schalm \& Beach (1936) and Delaplane et al. (1938) are no longer available, the debate over whether ' $H$. gallinarum' ever existed can never be fully settled. However, we feel that the evidence presented here leads to the conclusion that the early reports of ' $H$. gallinarum' as the causative agent of infectious coryza were incorrect.

We would like to dedicate this publication to the memory of $\mathrm{Dr}$ M. S. Hofstad, who was an early pioneer worker in many fields of avian bacteriology, including the avian haemophili.

This work was supported in part by funds provided by the USDA under the Animal Health Act of 1977, Public Law 95-113. The work was performed while the senior author was on sabbatical leave at the University of California, Davis. The financial support of the Australian Poultry Research Council for this leave is acknowledged.

\section{REFERENCES}

Biberstein, E. L. \& White, D. C. (1969). A proposal for the establishment of two new Haemophilus species. Journal of Medical Microbiology 2, 75-78.

Biberstein, E. L., Mini, P. D. \& Gills, M. G. (1963). Action of Haemophilus cultures on $\delta$-amino-levulinic acid. Journal of Bacteriology 86, 814-819.

Blackall, P. J. (1983). An evaluation of methods for the detection of carbohydrate fermentation in avian Haemophilus species. Journal of Microbiological Methods 1, 275-281.

Blackall, P. J. \& ReID, G. G. (1982). Further characterization of Haemophilus paragallinarum and Haemophilus avium. Veterinary Microbiology 7, 359-367.

De BLIECK, L. (1932). A haemoglobinophilic bacterium as the cause of contagious catarrh of the fowl. Veterinary Journal 88, 9-13.

Delaplane, J. P., Erwin, L. E. \& Stuart, H. O. (1934). A hemophilic bacillus as the cause of an infectious rhinitis. Rhode Island State College Bulletin no. 244, pp. 1-12.

Delaplane, J. P., Erwin, L. E. \& Stuart, H. O. (1938). The effect of the $X$-factor, of sodium chloride, and of the composition of the nutrient media upon the growth of the fowl coryza bacillus, Hemophilus gallinarum. Journal of Agricultural Research 56, 919-926.

Elliot, C. P. \& LewIS, M. R. (1934). A hemophilic bacterium as a cause of infectious coryza in the fowl. Journal of the American Veterinary Medical Association 37, 878-888.

HiNZ, K.-H. (1973). Beitrag zur Differenzierung von Haemophilus-Stammen aus Huhern. I. Mitteilung: Kulturelle und biochemische Untersuchungen. Avian Pathology 2, 211-229.

Kume, K., Sawata, A. \& Nakase, Y. (1978). Haemophilus infection in chickens. I. Characterization of
Haemophilus paragallinarum isolated from chickens affected with coryza. Japanese Journal of Veterinary Science 40, 65-73.

Malkinson, M., Machany, S., ARonovici, A., Davidov, K. \& WeismanN, Y. (1987). Mixed infection with Chamydia psittaci, fowl pox virus and Haemophilus gallinarum in broiler breeder chicks. Veterinary Record 120, 461-462.

McGaughey, C. A. (1932). Organisms of the $B$. influenzae group in fowls. Journal of Comparative Pathology 45, 58-66.

Mutters, R., Piechulla, K., Hinz, H.-K. \& ManNHEIM, W. (1985). Pasteurella avium (Hinz and Kunjara 1977) comb. nov. and Pasteurella volantium sp. nov. International Journal of Systematic Bacteriology 35, 5-9.

Narita, N., Hipolito, O. \& Bottino, J. A. (1978). Studies on infectious coryza. I. The biochemical and serological characteristics of 17 Haemophilus strains isolated in Brazil. Proceedings and Abstracts of the XVI World Poultry Congress 5, 689-692.

Nelson, J. B. (1933). Studies on an uncomplicated coryza of the domestic fowl. I. Isolation of a bacillus which produces a nasal discharge. Journal of Experimental Medicine 58, 289-295.

PAGE, L. A. (1962). Haemophilus infections in chickens. I. Characteristics of 12 Haemophilus isolates recovered from diseased chickens. American Journal of Veterinary Research 23, 85-95.

Reid, G. G. \& Blackall, P. J. (1987). A comparison of adjuvants for an inactivated infectious coryza vaccine. Avian Diseases 31, 59-63.

RIMLER, R. B. (1979). Studies on the pathogenic avian haemophili. Avian Diseases 23, 1006-1018.

Roberts, D. H., Hanson, B. S. \& Timms, L. (1964). Observations in the incidence and significance of Haemophilus gallinarum in outbreaks of respiratory 
disease among poultry in Great Britain. Veterinary Record 76, 1512-1516.

SCHALM, O. W. \& BEACH, J. R. (1936). Cultura
requirements of the fowl-coryza bacillus. Journal of Bacteriology 31, 161-169.

Thornton, A. M. \& Blackall, P. J. (1984). Serological classification of Australian isolates of Haemophi- lus paragallinarum. Australian Veterinary Journal 61, 251-253.

YAMAMOTO, R. (1984). Infectious coryza. In Diseases of Poultry, 8th edn., pp. 178-186. Edited by M. S. Hofstad, H. J. Barnes, B. W. Calnek, W. M. Reid \& H. W. Yoder, Jr. Ames : Iowa State University Press. 